\title{
Validation of the Injustice Experiences Questionnaire adapted for Use with Patients with Severe Osteoarthritis of the Knee
}

\author{
Esther Yakobov', Whitney Scott ${ }^{2}$, Michael Tanzer ${ }^{1}$, William Stanish ${ }^{3}$, Michael Dunbar ${ }^{3}$, Glen Richardson ${ }^{3}$, Michael JL Sullivan ${ }^{1 *}$ \\ ${ }^{1}$ Department of Psychology, McGill University, Montreal, Canada \\ 2Department of Psychology, Institute of Psychiatry, King's College London, London, United Kingdom \\ ${ }^{3}$ Department of Surgery, Dalhousie University, Halifax, Canada
}

\begin{abstract}
Objective: Recent research has linked perceptions of injustice to problematic recovery outcomes for individuals with musculoskeletal injuries. However, the measure currently used to assess perceived injustice is not readily applicable to individuals who have a pain condition, such as osteoarthritis (OA), where pain onset is insidious as opposed to traumatic. The purpose of this study was to validate a modified version of the Injustice Experiences Questionnaire (IEQ-chr) for patients with OA of the knee.
\end{abstract}

Methods: The IEQ-chr was administered along with measures of pain catastrophizing, fear of movement, depressive symptoms, pain severity and physical function to 110 individuals with severe OA of the knee.

Results: Principal component analyses yielded a factor structure similar to that in the original validation study. The IEQ-chr had high internal consistency (Chronbach alpha=0.88), and was significantly correlated with pain catastrophizing, fear of movement, depressive symptoms, pain severity and physical function. Regression analyses revealed that the IEQ-chr contributed significant unique variance to prediction of pain severity and physical function, beyond the variance accounted for by measures of pain catastrophizing and fear of movement.

Conclusions: The findings of the present study support the construct validity of the IEQ-chr in the context of osteoarthritis, and suggest that this measure may be useful in the psychosocial assessment of individuals at risk for adverse pain outcomes. The discussion addresses theoretical and clinical implications of these findings.

Keywords: Osteoarthritis; Perceived injustice; Pain; Disability; Depressive symptoms

\section{Introduction}

Considerable evidence indicates that psychological variables play a significant role in the experience of pain and disability. Pain catastrophizing and fear of movement are examples of psychological variables that have been associated with heightened levels of pain severity, physical disability, and depressive symptoms in a number of clinical pain populations [1-7]. Recent investigations suggest that perceptions of injustice associated with debilitating pain conditions are also implicated in problematic recovery following musculoskeletal injury [8-12].

Perceived injustice has been defined as a multidimensional construct comprising negative appraisals of the severity and irreparability of pain-related loss, attributions of blame, and a sense of unfairness [10]. There are indications that appraisals of injustice may trigger psychological and physiological changes that increase the intensity of pain and complicate recovery [11,13-15]. For individuals who have sustained musculoskeletal injuries, perceived injustice has been shown to prospectively predict the persistence of pain symptoms, more pronounced and prolonged disability, as well as the persistence of post-traumatic stress symptoms $[10,12,16,17]$. To date, research on the health and mental health consequences of perceived injustice has been conducted almost exclusively with patients with persistent pain following musculoskeletal injury. The role of perceived injustice as a determinant of adverse health and mental health outcomes associated with OA has not been investigated.

There is a basis for suggesting that perceptions of injustice may be relevant to the experience of severe OA. The majority of patients with severe OA are near retirement age $[18,19]$. A time of life that, for many, was intended to bring freedom from employment and realization of one's dreams is now replaced by pain, restricted mobility, and decreased quality of life. Narratives reflecting a sense of injustice are not uncommon in patients with severe OA $[20,21]$. The experiences of loss and unnecessary suffering consequent to OA may give rise to perceptions of injustice which in turn, might augment the experience of pain, distress and disability.

The aim of this study was to validate a version of the Injustice Experiences Questionnaire (IEQ) adapted for use with patients with OA. The instructional set of the original IEQ was modified to make it more suitable to the context of OA pain where pain onset is insidious as opposed to traumatic. The psychometric properties of the modified IEQ were examined in a sample of patients with severe OA of the knee. The pattern of findings was compared to previous research using the original version of the scale.

\section{Methods}

\section{Participants}

The sample consisted of 110 ( 67 women and 43 men) patients with severe OA of the knee. The mean age of the participants was 66.9 years,

*Corresponding author: Dr. Michael Sullivan, Department of Psychology, McGil University1205 Doctor Penfield Avenue, Montreal, QC H3A 1B1, Canada, Tel: 514398-5677; E-mail: michael.sullivan@mcgill.ca

Received April 22, 2014; Accepted May 27, 2014; Published May 30, 2014

Citation: Yakobov E, Scott W, Tanzer M, Stanish W, Dunbar M, et al. (2014) Validation of the Injustice Experiences Questionnaire adapted for Use with Patients with Severe Osteoarthritis of the Knee. J Arthritis 3: 130. doi:10.4172/2167. 7921.1000130

Copyright: (c) 2014 Yakobov E, et al. This is an open-access article distributed under the terms of the Creative Commons Attribution License, which permits unrestricted use, distribution, and reproduction in any medium, provided the original author and source are credited. 
ranging from 50 to 80 years. The majority of the sample was married $(85 \%)$ and had completed at least 12 years of education (90\%).

\section{Measures}

Perceived injustice: The modified Injustice Experiences Questionnaire (IEQ-chr) is a 12-item measure used to assess painrelated injustice perceptions [10]. The only difference between IEQchr and the original IEQ is the instructional set. Whereas the original scale asks individuals to respond to items in terms of how their injury affected their life, the IEQ-chr asks individuals to respond in terms of how their 'health condition' has affected their life. The suffix 'chr' was added to the scale acronym to distinguish it from the original measure. The IEQ measures cognitions associated with unfairness ("I can't believe this has happened to me"), perceived severity and irreparability of loss ("Nothing will ever make up for what I have gone through"), and blame ("I am suffering because of someone else negligence"). The IEQ uses a 5-point Likert-type scale with responses ranging from $0=$ "never" to $4=$ "all the time".

Catastrophizing: The Pain Catastrophizing Scale (PCS) was used to measure pain catastrophizing [22]. The PCS is a 13-item measure that assesses various thoughts and feelings related to the experience of pain. The PCS uses 4-point Likert-type scale with responses ranging from $0="$ not at all" to $4=$ "all the time." Item responses are summed to yield a total score. The scale and its subscales have been shown to have high internal consistency (Cronbach's [23] alphas : total= .87; rumination $=.87$, magnification $=.66$, helplessness $=.78$ ) and to be associated with measures of pain intensity and disability [22,24-26].

Depressive symptoms: The Patient Health Questionnaire-9 (PHQ9) is a 9-item instrument used to assess the severity of depressive symptoms [27]. Respondents are asked to indicate the frequency with which they experience each of nine symptoms that are considered in the diagnostic criteria for major depressive symptoms [27]. Ratings are made on a 4-point frequency scale with the endpoints 0 "not at all" and 3 "everyday". The scores range from 0 to 27 with higher scores representing worse symptoms of depressive symptoms. A clinical cut score of 15 has been suggested to identify individuals with clinically significant depressive symtpoms. Reliability and validity of the PHQ-9 have been demonstrated in various clinical populations [28-30].

Fear of movement/Re-injury: The Tampa Scale for Kinesiophobia -13 (TSK-13) is a 13-item measure used to assess fear of movement and contains 13 items from the original TSK-17 [31,32]. The TSK-13 uses a 4-point Likert-type scale with responses ranging from 1="strongly disagree" to $4=$ "strongly agree". High scores represent more intense fear of movement. Elevated scores on the original and shortened versions of TSK have been associated with a wide range of manifestations of behavioural avoidance and physical disability in patients with various conditions including OA [3,33-37]. The validity and internal reliability of the shortened TSK have been confirmed (Cronbach's alpha $=.86$ ) [32,34].

Pain and function: The Western Ontario and McMaster University Osteoarthritis Index (WOMAC) is a self-administrated questionnaire used to evaluate pain, stiffness and physical function in individuals with osteoarthritis of the hip or knee [38]. The WOMAC uses a 5-point Likert scale with responses ranging from "none" to "extreme". For the purposes of the current study, only the subscale scores for pain and function are reported. Higher scores represent worse pain and higher disability. The scores of WOMAC Pain and WOMAC Function were converted to 0-100 ranges to allow for cross-scale and cross-study comparison $[39,40]$. The WOMAC has been shown to be a valid and reliable measure for assessing pain and disability in the context of $\mathrm{OA}$ $[38,41,42]$.

\section{Procedure}

Patients with severe OA of the knee were invited to participate in the current study at one of three collaborating hospitals. For the purposes of the present study, severe OA of the knee was operationalized as a diagnosis of primary $\mathrm{OA}$ of the knee for which the patients were scheduled to undergo total knee arthroplasty within the next 4 weeks. Patients were informed that the research was concerned with the physical, psychological and social aspects of pain associated with OA. All patients signed a consent form and received \$25 as compensation for completing the questionnaires. The research was approved by the Research Ethics Boards of the McGill University Health Centre, the Hôpital Maisonneuve-Rosemont, and the Capital Health Authority of Nova Scotia.

\section{Data analysis}

All measures used in psychometric analyses showed a normal distribution with values of skewness below 3 and values of kurtosis below 10. Descriptive statistics were computed on sample characteristics and independent sample $t$-tests were computed to investigate sex differences on all measures. A principal component analysis (PCA) with oblique rotation was perform Catastrophizing:ed to assess the structure of the IEQ-chr. Based on previous research examining the psychometric properties of the original IEQ, it was expected that the PCA would yield a two-component solution (blame/unfairness and severity/irreparability). Construct validity was assessed by examining correlations between the IEQ-chr and measures of pain catastrophizing, fear of movement, depressive symptoms, pain and physical function.

Hierarchical regression analyses were used to assess whether the IEQ-chr contributed significantly to the prediction of pain, physical function, and depressive symptoms beyond the variance accounted for by pain catastrophizing, and fear of movement. All tolerance coefficients in the regression results were greater than .49 indicating no problems of multi collinearity.

\section{Results}

\section{Sample characteristics}

Demographic information and means and standard deviations on assessment measures are summarized in Table 1. Men and women did not differ significantly on any of the study variables. The distribution of age, body mass index (BMI), and WOMAC pain and function scores were comparable (less than one standard deviation from the mean) to those reported in previous studies with patients with OA of the knee [43-45]. The scores on the PHQ-9, and PCS were also comparable to those reported research on patients with OA of the knee $[3,45]$. The majority of patients scored below the cut off for clinically significant depressive symptoms. Scores on the IEQ-chr were lower (greater than one standard deviation) than the IEQ scores reported on patients with musculoskeletal injuries $[9,10]$.

\section{Structure and internal consistency of the IEQ-chr}

Principal component analysis with oblique rotation yielded a twocomponent solution with eigenvalues greater than 1 . The loadings of the pattern matrix were similar to those found in the original validation study (Table 2). The first component labelled blame/unfairness accounted for $46 \%$ of the total variance. The second component labelled severity/irreparability accounted for $11 \%$ of the variance. The 
Citation: Yakobov E, Scott W, Tanzer M, Stanish W, Dunbar M, et al. (2014) Validation of the Injustice Experiences Questionnaire adapted for Use with Patients with Severe Osteoarthritis of the Knee. J Arthritis 3: 130. doi:10.4172/2167-7921.1000130

Page 3 of 6

correlation between the two components was .42. The coefficient alpha was .88 and item total correlation coefficients ranged between .38 and .72 , indicating good internal consistency.

\section{Construct validity}

As presented in Table 3, the construct validity of the IEQ-chr was supported by significant correlations with pain severity $(\mathrm{r}=.41, \mathrm{p}<.001)$, physical function $(\mathrm{r}=.44, \mathrm{p}<.001)$, depressive symptoms $(\mathrm{r}=.48$, $\mathrm{p}<.001)$, fear of movement $(\mathrm{r}=.47, \mathrm{p}<.001)$, and pain catastrophizing $(\mathrm{r}=.67, \mathrm{p}<.001)$. Age was inversely correlated with pain intensity $(\mathrm{r}=-$ $.28, \mathrm{p}<.05)$, physical function $(\mathrm{r}=-.20, \mathrm{p}<.05)$ and BMI $(\mathrm{r}=-.36, \mathrm{p}<.001)$ BMI was also correlated with pain intensity $(\mathrm{r}=.24, \mathrm{p}<.05)$.

\section{Contributions of perceived injustice to the prediction of pain, function and depression}

Three separate hierarchical regression analyses were conducted to examine the unique contribution of the IEQ-chr to the prediction of pain severity, physical function, and depressive symptoms after controlling for pain catastrophizing and fear of movement. In each regression, age, sex, and BMI were entered in the first step. In the second step pain catastrophizing and fear of movement were entered, followed by perceived injustice in the third step.

Table 4 shows the results of the regression analyses for the prediction of WOMAC pain. The demographic variables entered in the first step

Table 1: Sample Characteristics.

\begin{tabular}{|l|l|l|l|l|}
\hline Pre surgical variables & Women N=67 & Men N=43 & $\boldsymbol{P}$ & Total \\
\hline Age & $67.0(8.6)$ & $66.7(7.8)$ & ns & $66.8(8.3)$ \\
\hline BMI & $31.2(5.9)$ & $30.6(4.0)$ & ns & $31.0(5.3)$ \\
\hline Pain & $54.0(16.3)$ & $50.6(18.7)$ & ns & $52.7(17.2)$ \\
\hline Function & $55.7(16.8)$ & $55.3(19.3)$ & ns & $55.6(17.7)$ \\
\hline PHQ-9 & $6.7(6.6)$ & $6.3(7.7)$ & ns & $6.6(7.0)$ \\
\hline PCS & $12.9(11.4)$ & $11.2(9.2)$ & ns & $12.2(10.6)$ \\
\hline TSK-13 & $27.9(8.5)$ & $28.6(8.3)$ & ns & $28.1(8.4)$ \\
\hline IEQ-chr & $9.3(9.0)$ & $7.7(7.1)$ & ns & $8.7(8.3)$ \\
\hline
\end{tabular}

Note: $N=110$. BMl=body mass index; Pain = WOMAC Pain Score; Function = WOMAC Physical Function Score; PHQ-9 = Patient Health Questionnaire; PCS = Pain Catastrophizing Scale; TSK-13 = Tampa Scale for Kinesiophobia; IEQ-chr = Perceived Injustice Scale

Table 2: IEQ Rotated factor Loadings (pattern matrix).

\begin{tabular}{|l|l|l|l|l|}
\hline Item\# & F1 & F2 & Item total r \\
\hline IEQ9 & $\begin{array}{l}\text { Nothing will ever make up for all that I have } \\
\text { gone through }\end{array}$ & .83 & .66 \\
\hline IEQ8 & $\begin{array}{l}\text { I worry that my condition is not being taken } \\
\text { seriously }\end{array}$ & .82 & .66 \\
\hline IEQ1 & $\begin{array}{l}\text { Most people don't understand how severe my } \\
\text { condition is }\end{array}$ & .71 & .56 \\
\hline IEQ3 & $\begin{array}{l}\text { I am suffering because of someone else's } \\
\text { negligence }\end{array}$ & .71 & .38 \\
\hline IEQ12 & I can't believe this has happened to me & .65 & .57 \\
\hline IEQ11 & $\begin{array}{l}\text { I am troubled by fears that I may never achieve } \\
\text { my dreams }\end{array}$ & .60 & .59 \\
\hline IEQ7 & It all seems so unfair & .54 & .38 & .72 \\
\hline IEQ10 & $\begin{array}{l}\text { I feel as if I have been robbed of something } \\
\text { very precious }\end{array}$ & .51 & .38 & .68 \\
\hline IEQ4 & No one should have to live this way & .44 & .49 & .71 \\
\hline IEQ2 & My life will never been the same & .68 & .65 \\
\hline IEQ5 & I just want to have my life back & .75 & .44 \\
\hline IEQ6 & I feel that this has affected me in a permanent way & .85 & .52 \\
\hline Values in bold are factor loadings greater than 50 & & \\
\hline
\end{tabular}

Values in bold are factor loadings greater than .50
Table 3: Correlations among pre-surgery pain-related psychological measures.

\begin{tabular}{|l|l|l|l|l|l|l|}
\hline & 1 & 2 & 3 & 4 & 5 & 6 \\
\hline IEQ-chr & & & & & & \\
\hline PCS & $.67^{* *}$ & & & & & \\
\hline TSK-13 & $.47^{* *}$ & $.51^{* *}$ & & & & \\
\hline Pain & $.41^{* *}$ & $.32^{* *}$ & $.20^{*}$ & & & \\
\hline Function & $.44^{* *}$ & $.36^{* *}$ & $.33^{* *}$ & $.72^{* *}$ & & \\
\hline PHQ-9 & $.48^{* *}$ & $.50^{* *}$ & $.44^{* *}$ & $.28^{*}$ & $.36^{* *}$ & \\
\hline
\end{tabular}

Note: $N=110$; Pain WOMAC Pain Score; Function = WOMAC Physical Function Score; PCS = Pain Catastrophizing Scale; PHQ-9 = Patient Health Questionnaire; TSK-13 = Tampa Scale for Kinesiophobia; IEQ-chr = Perceived Injustice Scale ${ }^{*} p<.05,{ }^{* *} p \leq .001$

Table 4: Regression analyses examining the role of perceived injustice in the prediction of pain severity.

\begin{tabular}{|c|c|c|c|}
\hline & Beta & $\mathbf{R}^{2}$ change & F change \\
\hline \multicolumn{2}{|c|}{ Dependent = Pain Intensity } & & \\
\hline Step 1 & & & \\
\hline Age & $-.19^{\star}$ & & \\
\hline Sex & -.06 & & $4.37(3,106)^{\star}$ \\
\hline BMI & .15 & .11 & \\
\hline Step 2 & & & \\
\hline PCS & .02 & & $4.86(2,104)^{\star}$ \\
\hline TSK-13 & .04 & .08 & \\
\hline Step 3 & & & $8.70(1,103)^{*}$ \\
\hline IEQ-chr & $.35^{\star}$ & .06 & \\
\hline
\end{tabular}

Note. $N=110$. Pain Intensity = WOMAC Score; BMI=body mass index; PCS = Pain Catastrophizing Scale; TSK-13 = Tampa Scale for Kinesiophobia; IEQ-chr = Perceived Injustice Scale. Standardized Beta weights are from the final regression equation.

${ }^{*} p<.05 ;{ }^{* *} p<.001$

contributed significant variance to the prediction of pain severity. Pain catastrophizing and fear of movement were entered in the second step and contributed significant variance to the prediction of pain severity. Perceived injustice was entered in the third step and also contributed significantly to the prediction of pain severity, and accounted for $6 \%$ additional variance in WOMAC pain scores. Examination of the standardized beta weights from the final regression equation indicated that of the three psychological variables, only the IEQ-chr $(\beta=.35$, $p<.05)$ contributed significant unique variance to the prediction of pain severity.

Table 5 shows the results of the regression analyses for the prediction of WOMAC function. Demographic variables were entered in the first step but did not contribute significant variance to the prediction of physical function. Pain catastrophizing and fear of movement were entered in the second step and contributed significant variance to the prediction of WOMAC function. Perceived injustice was entered in the third step and also contributed significantly to the prediction of physical function, accounting for $6 \%$ additional variance in WOMAC function scores. Examination of the standardized beta weights from the final regression equation indicated that of the three psychological variables, only the IEQ-chr $(\beta=.34, p<.05)$ contributed significant unique variance to the prediction of WOMAC function scores.

Table 6 shows the results of the regression analyses for the prediction of depressive symptoms. Demographic variables were entered in the 
Table 5: Regression analyses examining the role of perceived injustice in the prediction of physical function.

\begin{tabular}{|c|c|c|c|}
\hline & Beta & $\mathrm{R}^{2}$ change & F change \\
\hline \multicolumn{4}{|c|}{ Dependent = Function } \\
\hline \multicolumn{4}{|l|}{ Step 1} \\
\hline Age & -.11 & & \\
\hline Sex & .02 & & \\
\hline BMI & .14 & .06 & $2.09(3,106)$ \\
\hline \multicolumn{4}{|l|}{ Step 2} \\
\hline PCS & .02 & & \\
\hline TSK-13 & .17 & .14 & $9.32(2,104)^{* *}$ \\
\hline \multicolumn{4}{|l|}{ Step 3} \\
\hline IEQ-chr & $.34^{*}$ & .06 & $8.41(1,103)^{*}$ \\
\hline
\end{tabular}

Note. $N=110$. Function = WOMAC Physical Function Score, BMI=body mass index ; PCS = Pain Catastrophizing Scale; TSK-13 = Tampa Scale for Kinesiophobia IEQ-chr = Perceived Injustice Scale. Standardized Beta weights are from the final regression equation.

${ }^{*} p<.05 ;{ }^{* *} p<.001$

Table 6: Regression analyses examining the role of perceived injustice in the prediction of depressive symptoms.

\begin{tabular}{|c|l|l|l|}
\hline \multicolumn{2}{|c|}{ Beta } & $R^{2}$ change & \\
\hline \multicolumn{2}{|l|}{ Dependent = Depressive symptoms } & & \\
\hline Step 1 & & & \\
\hline Age & -.09 & & $.74(3,106)$ \\
\hline Sex & -.01 & .02 & \\
\hline BMI & -.04 & & \\
\hline Step 2 & & & $21.14(2,104)^{\star *}$ \\
\hline PCS & $.24^{*}$ & .28 & \\
\hline TSK-13 & $.22^{*}$ & & $3.68(1,103)$ \\
\hline Step 3 & & .02 & \\
\hline IEQ-chr & $.21 \dagger$ & & \\
\hline
\end{tabular}

Note. $N=110$. PCS = Pain Catastrophizing Scale; $\mathrm{BMI}=$ body mass index; TSK-13 = Tampa Scale for Kinesiophobia; IEQ-chr = Perceived Injustice Scale. Standardized Beta weights are from the final regression equation.

$\dagger p=.06 ;{ }^{*} p<.05 ;{ }^{* *} p<.001$

first step but did not contribute significant variance to the prediction of depressive symptoms. Pain catastrophizing and fear of movement were entered in the second step and contributed significant variance to the prediction of symptoms of depression. Perceived injustice was entered in the last step but did not contribute significantly to the prediction of depressive symptoms. Examination of the standardized beta weights from the final regression equation revealed that fear of movement $(\beta=.22, \mathrm{p}<.05)$ and the pain catastrophizing $(\beta=.24, \mathrm{p}<.05)$ contributed significant unique variance to the prediction of symptoms of depression while the predictive value of the IEQ-chr was only marginally significant $(\beta=.21, \mathrm{p}=.06)$.

\section{Discussion}

The aim of the current study was to evaluate the psychometric properties of the IEQ-chr in the context of OA of the knee. The original measure of perceived injustice (IEQ) was developed for use in individuals with musculoskeletal injuries. In the current version, the instructional set was modified to make it suitable to the context of pain and suffering associated with OA, which is characterized by insidious onset as opposed to traumatic onset.

Consistent with the original IEQ validation study conducted with individuals with various musculoskeletal injuries [10], the principal component analysis of the IEQ-chr yielded a two-component solution (blame/unfairness and severity/irreparability of loss). The scale had high internal consistency (alpha $=.88$ ). Replicating research conducted with the original IEQ, the construct validity of IEQ-chr was supported by significant correlations with measures of pain catastrophizing, fear of movement, depression, pain intensity and physical function [8$11,16,46]$.

Consistent with previous findings, in the current study perceived injustice showed a strong correlation with pain catastrophizing $(r=.67)$ [10]. One explanation that has been proposed for the strong correlation between these variables is the conceptual overlap between subcomponents of perceived injustice and pain catastrophizing. It has been suggested that the "severity and irreparability" component of the IEQ overlaps with the 'magnification' component of the PCS. However, blame and unfairness dimensions of IEQ are not reflected in the item content of the PCS, suggesting that these constructs are at least partially distinct $[10,11,47]$.

Zero-order correlations revealed that the IEQ accounted for $17 \%$, $19 \%$ and $23 \%$ of the variance in pain severity, physical function and depression, respectively. Regression analyses revealed that perceived injustice contributed significant unique variance to the prediction of pain intensity, and physical function beyond the variance accounted for by pain catastrophizing and fear of movement. Pain catastrophizing and fear of movement contributed unique variance to the prediction of depressive symptoms while perceived injustice, was marginally significant $(p=.06)$. In previous research, pain catastrophizing and fear of movement have been identified as two of the most robust predictors of problematic health and mental health outcomes associated with OA $[3,48-50]$. The present findings suggest that perceptions of injustice are as important, if not more important, than previously identified psychosocial risk factors in the prediction of problematic health and mental health outcomes associated with OA.

The total IEQ-chr score in the current sample of patients with OA was substantially lower than that previously reported in samples of individuals who had sustained musculoskeletal injuries. Sullivan and colleagues reported a mean IEQ score of $25.1(\mathrm{SD}=1.8)$ in individuals with whiplash injuries, and a mean IEQ score of $17.3(\mathrm{SD}=12.2)$ in individuals who have sustained work-related musculoskeletal injuries [10]. In the present study, the mean IEQ-chr score was $8.7(\mathrm{SD}=8.3)$. There could be several explanations to this finding.

Firstly, when examining the phenomenology of perceived injustice in injury and non-injury populations the main distinction arising between the individuals in these two samples is the salience of targets to blame for their health condition. Osteoarthritis patients, given the insidious nature of their condition, may not have one such identifiable source for the onset of their pain. Indeed, 99 out of 110 individuals in the current sample reported a score of " 0 " on question assessing attributions of blame ("I am suffering because of someone else's negligence"). The mean score for this particular question in the present sample was .18 ( $\mathrm{SD}=.64)$, lowest of all items on the IEQ-chr. The mean score for this item in whiplash-injured patients was 10 times higher $(\mathrm{M}=1.85 ; \mathrm{SD}=1.60)$ [9].

Other factors that may account for lower perceptions of injustice in individuals with $\mathrm{OA}$ include age, the nature of symptom onset, and treatment context. The majority of patients with musculoskeletal injuries are significantly younger than patients with OA $[9,18,19]$. Postinjury life for patients with musculoskeletal injuries if often associated with loss of employment, loss of independence, possible financial losses, and chronic pain $[51,52]$. It has been suggested that health related losses are perceived to be less severe for an older person than for a younger person as older individuals have a larger portion of life of enjoyment 
Citation: Yakobov E, Scott W, Tanzer M, Stanish W, Dunbar M, et al. (2014) Validation of the Injustice Experiences Questionnaire adapted for Use with Patients with Severe Osteoarthritis of the Knee. J Arthritis 3: 130. doi:10.4172/2167-7921.1000130

and accomplishment behind them [53]. Thus, having to live with a debilitating condition at a young age might be perceived more unjust than developing painful and debilitating condition at a later stage in life. Due to the insidious nature of OA, patients with OA might also have more time to adjust to their medical status, compared to younger individuals with a sudden onset of painful condition.

Another difference between patients with $\mathrm{OA}$ and patients with musculoskeletal injuries is the treatment context. Injury, as a result of a work injury or a motor vehicle accident, is managed within an insurance context where relations between clients and insurer representatives can become adversarial, fueling the injured person's perceptions of injustice [11]. Moreover, legal representatives have a vested interest in maintaining their client's perceptions of injustice [11]. The process of litigation for compensation has been consistently associated with pain severity and prolonged disability [54,55].

Therefore, the salience of target for blame, age, the onset of pain, and treatment context may partially explain why perceived injustice in the current OA sample was lower compared to injury samples. However, in spite of the lower IEQ-chr scores in the current sample, perceived injustice still emerged as a significant predictor of pain severity and disability after controlling for measures of pain, catastrophizing, and fear of movement.

Research is beginning to elucidate the processes by which perceptions of injustice might impact on recovery outcomes. For example, research emerging from social psychology indicates that perceptions of injustice give rise to anger responses [56,57]. There is also research to show that anger contributes to the experience of greater pain intensity through disruption of endogenous opioid mechanisms $[58,59]$. Increased muscle reactivity resulting from anger is also thought to be implicated in heightened experience of pain [60]. Several investigations reported associations between anger, pain, disability, and poor self-efficacy in patients with chronic pain conditions including arthritis [13,14,61-63]. Thus, anger arising from perceptions of injustice may be one vehicle through which perceived injustice impacts on pain in individuals with OA. Emotional distress, attentional focus on themes related to injustice and maladaptive coping have also been proposed as possible mechanisms by which perceived injustice might impact on pain outcomes [11].

The results of this study add to the mounting evidence highlighting the significance of perceived injustice in the context of pain and physical disability. The present results also suggest that assessment of perceived injustice in patients with $\mathrm{OA}$ of the knee might permit identification of individuals at-risk for problematic health and mental health outcomes. Based on previous research with individuals with chronic pain, cognitive behavioural approaches to anger management and acceptance-based interventions may be beneficial in reducing perceptions of injustice in individuals with OA [64-66].

The current study has several limitations. The correlational design of the study precludes strong statements about the direction of causality. For example, while perceptions of injustice may augment pain intensity, it is possible that the experience of severe pain may increase patients' of perceptions of injustice. In addition, the size of the study sample was modest, thus inviting caution in generalizing the findings to the wider OA population. Despite these limitations, this study is the first to provide support for the validity of a measure of perceived injustice in patients with OA. Results indicated that the IEQ-chr was associated with increased pain and disability, even when controlling for pain catastrophizing and fear of movement. Future research is needed to investigate whether the IEQ-chr scale can be used as a screening measure to identify individuals with $\mathrm{OA}$ who might be at risk for problematic health or mental health outcomes.

\section{References}

1. Edwards RR, Cahalan C, Mensing G, Smith M, Haythornthwaite JA (2011) Pain, catastrophizing, and depression in the rheumatic diseases. Nat Rev Rheumato 7: 216-224.

2. Campbell CM, Kronfli T, Buenaver LF, Smith MT, Berna C, et al. (2010) Situational versus dispositional measurement of catastrophizing: associations with pain responses in multiple samples. J Pain 11: 443-53 e2

3. Sullivan MJL, Tanzer M, Stanish W, Fallaha M, Keefe FJ, et al. (2009) Psychological determinants of problematic outcomes following Total Knee Arthroplasty. Pain 143: 123-129.

4. Linton SJ (2002) New Avenues for the Prevention of Chronic Musculoskeletal Pain and Disability. Elsevier,Amsterdam

5. Lee Y, Chibnik L, Lu B, Wasan A, Edwards R, et al. (2009) The relationship between disease activity, sleep, psychiatric distress and pain sensitivity in rheumatoid arthritis: a cross-sectional study. Arthritis Res Ther 11: R160.

6. Vlaeyen JW, Kole-Snijders AM, Boeren RG, van Eek H (1995) Fear of movement/ (re)injury in chronic low back pain and its relation to behavioral performance. Pain 62: 363-372.

7. Archer KR, Seebach CL, Mathis SL, Riley LH, 3rd, Wegener ST (2014) Early postoperative fear of movement predicts pain, disability, and physical health 6 months after spinal surgery for degenerative conditions. Spine J 14: 759-769.

8. Scott W, Sullivan M (2012) Perceived injustice moderates the relationship between pain and depressive symptoms among individuals with persistent musculoskeletal pain. Pain Res Manag 17: 335-340.

9. Scott W, Trost Z, Milioto M, Sullivan MJ (2013) Further Validation of a Measure of Injury-Related Injustice Perceptions to Identify Risk for Occupational Disability: A Prospective Study of Individuals with Whiplash Injury. J OccupRehabil 23 557-565.

10.Sullivan MJL, Adams H, Horan S, Maher D, Boland D, et al. (2008) The role of perceived injustice in the experience of chronic pain and disability: scale development and validation. J OccupRehabil 18: 249-261.

11.Sullivan MJL, Scott W, Trost Z (2012) Perceived injustice: a risk factor for problematic pain outcomes. Clin J Pain 28: 484-488.

12.Sullivan ML, Davidson N, Garfinkel B, Siriapaipant N, Scott W (2009) Perceived Injustice is Associated with Heightened Pain Behavior and Disability in Individuals with Whiplash Injuries. Psychollnj Law 2: 238-247.

13.Scott W, Trost Z, Bernier E, Sullivan MJ (2013) Anger differentially mediates the relationship between perceived injustice and chronic pain outcomes. Pain 154: 1691-1698.

14. Trost Z, Vangronsveld K, Linton SJ, Quartana PJ, Sullivan MJ (2012) Cognitive dimensions of anger in chronic pain. Pain 153: 515-517.

15.Goodin BR, McGuire L, Allshouse M, Stapleton L, Haythornthwaite JA, et al (2009) Associations between catastrophizing and endogenous pain-inhibitory processes: sex differences. J Pain 10: 180-190.

16.Sullivan MJL, Adams H, Martel MO, Scott W, Wideman T (2011) Catastrophizing and perceived injustice: risk factors for the transition to chronicity after whiplash injury. Spine 36: 244-249.

17.Sullivan MJL, Thibault P, Simmonds MJ, Milioto M, Cantin AP, et al. (2009) Pain perceived injustice and the persistence of post-traumatic stress symptoms during the course of rehabilitation for whiplash injuries. Pain 145: 325-331.

18.Arthritis Alliance of Canada. The impact of arthritis in Canada: today and over the next 30 years 2011 [11-4, 28-32].

19.Neustadt DH (2006) Intra-articular injections for osteoarthritis of the knee. ClevClin J Med 73: 897-898.

20.Demierre M, Castelao E, Piot-Ziegler C (2011) The long and painful path towards arthroplasty: a qualitative study. J Health Psychol 16: 549-560.

21.Toye FM, Barlow J, Wright C, Lamb SE (2006) Personal meanings in the construction of need for total knee replacement surgery. SocSci Med 63: 43-53. 
Citation: Yakobov E, Scott W, Tanzer M, Stanish W, Dunbar M, et al. (2014) Validation of the Injustice Experiences Questionnaire adapted for Use with Patients with Severe Osteoarthritis of the Knee. J Arthritis 3: 130. doi:10.4172/2167-7921.1000130

22.Sullivan MJL, Bishop S, Pivik J (1995) The Pain Catastrophizing Scale: Development and validation. Psychol Assess 7: 524-532.

23.Cronbach LJ (1951) Coefficient alpha and the internal structure of tests. Psychometrika 16: 297-334.

24.Sullivan MJL, Neish NR (1998) Catastrophizing, anxiety and pain during dental hygiene treatment. Community Dent Oral Epidemiol 26: 344-349.

25.Sullivan MJL, Stanish W, Sullivan ME, Tripp D (2002) Differential predictors of pain and disability in patients with whiplash injuries. Pain Res Manag 7: 68-74.

26.Sullivan MJL, Stanish WD (2003) Psychologically-based occupational rehabilitation: the Pain-Disability Prevention Program. Clin J Pain 19: 97-104.

27.Spitzer RL, Williams JBW, Kroenke K (1999) Patient Health Questionnaire - 9. Prime MD Today. Pfizer Inc, New York

28.Gilbody S, Richards D, Brealey S, Hewitt C (2007) Screening for depression in medical settings with the Patient Health Questionnaire (PHQ): a diagnostic meta-analysis. J Gen Intern Med 22: 1596-602.

29.Huang FY, Chung H, Kroenke K, Delucchi KL, Spitzer RL (2006) Using the Patient Health Questionnaire-9 to measure depression among racially and ethnically diverse primary care patients. J Gen Intern Med 21: 547-552.

30.Li C, Friedman B, Conwell Y, Fiscella K (2007) Validity of the Patient Health Questionnaire 2 (PHQ-2) in identifying major depression in older people. J Am GeriatrSoc 55: 596-602.

31.Kori S, Miller R, Todd D (1990) Kinesiophobia: A new view of chronic pain behavior. Pain Manag 3: 35-43.

32. Clark M, Kori S, Brockel J (1996) Kinesiophobia and chronic pain psychometric characteristics and factor analysis of the Tampa scale. Proceedings of the 15th annual scientific meeting of the American Pain Society, Abstracts 15: 77. Washington, DC.

33.Crombez G, Vlaeyen JW, Heuts PH, Lysens R (1999) Pain-related fear is more disabling than pain itself: evidence on the role of pain-related fear in chronic back pain disability. Pain 80: 329-339.

34.Geisser M, Haig A, Theisen M (2000) Activity Avoidance and Function in Persons with Chronic Back Pain. J Occup Rehabil 10: 215-227.

35.Goubert L, Crombez G, Van Damme S (2004) The role of neuroticism, pain catastrophizing and pain-related fear in vigilance to pain: a structural equations approach. Pain 107: 234-241.

36.Picavet HS, Vlaeyen JW, Schouten JS (2002) Pain catastrophizing and kinesiophobia: predictors of chronic low back pain. Am J Epidemiol 156: 1028-1034.

37.Roelofs J, Goubert L, Peters ML, Vlaeyen JW, Crombez G (2004) The Tampa Scale for Kinesiophobia: further examination of psychometric properties in patients with chronic low back pain and fibromyalgia. Eur J Pain 8: 495-502.

38.Bellamy N, Buchanan WW, Goldsmith CH, Campbell J, Stitt LW (1988) Validation study of WOMAC: a health status instrument for measuring clinically important patient relevant outcomes to antirheumatic drug therapy in patients with osteoarthritis of the hip or knee. J Rhumatol 15: 1833-1840.

39.Bischoff-Ferrari HA, Lingard EA, Losina E, Baron JA, Roos EM, et al. (2004) Psychosocial and geriatric correlates of functional status after total hip replacement. Arthritis Rheum 51: 829-835

40.Bullens PH, van Loon CJ, de Waal Malefijt MC, Laan RF, Veth RP (2001) Patien satisfaction after total knee arthroplasty: a comparison between subjective and objective outcome assessments. J Arthroplasty 16: 740-747.

41.Bellamy N (1989) Pain assessment in osteoarthritis: experience with the WOMAC osteoarthritis index. Semin Arthritis Rheu 18: 14-17.

42.Bellamy N, Kean WF, Buchanan WW, Gerecz-Simon E, Campbell J (1992) Double blind randomized controlled trial of sodium meclofenamate (Meclomen) and diclofenac sodium (Voltaren): post validation reapplication of the WOMAC Osteoarthritis Index. J Rheumatol 19: 153-159.

43.Nunez M, Nunez E, del Val Luis J, Ortega R, Segur J, et al. (2007) Health-related quality of life in patients with osteoarthritis after total knee replacement: Factors influencing outcomes at 36 months of follow-up. Osteoarthritis Cartilage 15: 1001-1007.

44.Papakostidou I, Dailiana Z, Papapolychroniou T, Liaropoulos L, Zintzaras E, et al. (2012) Factors affecting the quality of life after total knee arthroplasties: a prospective study. BMC Musculoskelet Disord 13: 116.
45.Sullivan MJL, Tanzer M, Reardon G, Amirault D, Dunbar M, et al. (2011) The role of presurgical expectancies in predicting pain and function one year following total knee arthroplasty. Pain 152: 2287-2293.

46.Rodero B, Luciano JV, Montero-Marin J, Casanueva B, Palacin JC, et al. (2012) Perceived injustice in fibromyalgia: Psychometric characteristics of the Injustice Experience Questionnaire and relationship with pain catastrophising and pain acceptance. J Psychosom Res 73: 86-91.

47.Sullivan MJL, Thorn B, Haythornthwaite JA, Keefe F, Martin M, et al. (2001) Theoretical perspectives on the relation between catastrophizing and pain. Clin J Pain 17: 52-64.

48. Heuts PH, Vlaeyen JW, Roelofs J, de Bie RA, Aretz K, et al. (2004) Pain-related fear and daily functioning in patients with osteoarthritis. Pain 110: 228-235.

49.Keefe FJ, Lefebvre JC, Egert JR, Affleck G, Sullivan MJ, et al. (2000) The relationship of gender to pain, pain behavior, and disability in osteoarthritis patients: the role of catastrophizing. Pain 87: 325-334.

50.Somers TJ, Keefe FJ, Pells JJ, Dixon KE, Waters SJ, et al. (2009) Pain catastrophizing and pain-related fear in osteoarthritis patients: relationships to pain and disability. J Pain Symptom Manage 37: 863-872.

51.Lyons R, Sullivan MJL (1998) Curbing loss in illness and disability. In: Harvey $\mathrm{J}$, (eds.). Perspectives on Personal and Interpersonal Loss. Taylor \& Francis, New York. p. 579-605

52.Montada $L$ (1992) Attribution of responsibility for losses and perceived injustice. In: Montada L, Sigrun-Heide F, Lerner MJ (eds.) Life crises and experiences of loss in adulthood. Lawrence Erlbaum and Associates. Hillsdale, New Jersey.

53.Shaw AB (1994) In defence of ageism. J Med Ethics 20: 188-91, 94

54.Blyth FM, March LM, Nicholas MK, Cousins MJ (2003) Chronic pain, work performance and litigation. Pain 103: 41-7.

55.Turk DC, Okifuji A (1996) Perception of traumatic onset, compensation status, and physical findings: impact on pain severity, emotional distress, and disability in chronic pain patients. J Behav Med 19: 435-453.

56. Mikula G, Scherer KR, Athenstaedt U (1998) The role of injustice in the elicitation of differential emotional reactions. Pers Soc Psychol Bull 24:769 -783.

57.Miller DT (2001) Disrespect and the experience of injustice. Annu Rev Psychol 52: 527-553.

58.Bruehl S, Chung OY, Burns JW (2006) Anger expression and pain: an overview of findings and possible mechanisms. J Behav Med 29: 593-606.

59.Bruehl S, Chung OY, Burns JW, Diedrich L (2007) Trait anger expressiveness and pain-induced beta-endorphin release: support for the opioid dysfunction hypothesis. Pain 130: 208-15.

60.Burns JW (1997) Anger management style and hostility: predicting symptomspecific physiological reactivity among chronic low back pain patients. J Behav Med 20: 505-22.

61.Burns JW, Holly A, Quartana P, Wolff B, Gray E, et al. (2008) Trait ange management style moderates effects of actual ("state") anger regulation on symptom-specific reactivity and recovery among chronic low back pain patients. Psychosom Med 70: 898-905.

62.Greenwood KA, Thurston R, Rumble M, Waters SJ, Keefe FJ (2003) Anger and persistent pain: current status and future directions. Pain 103: 1-5.

63. Treharne GJ, Lyons AC, Booth DA, Mason SR, Kitas GD (2004) Reactions to disability in patients with early versus established rheumatoid arthritis. Scand J Rheumatol 33: 30-38

64.McCracken LM, Eccleston C (2003) Coping or acceptance: What to do about chronic pain? Pain 105: 197 - 204.

65.Graham JE, Lobel M, Glass P, Lokshina I (2008) Effects of written ange expression in chronic pain patients: making meaning from pain. J Behav Med 31: 201-12.

66. Eifert G, McKay M, Forsyth J (2006) Act on life not on anger. New Harbinger Publications, Oakland, California. 